\title{
The Inventory Model for Deteriorating Items under Conditions Involving Cash Discount and Trade Credit
}

\author{
Kun-Jen Chung ${ }^{1,2}$, Jui-Jung Liao ${ }^{3}{ }^{-}$, Shy-Der Lin ${ }^{4}$ and Sheng-Tu Chuang ${ }^{5}$ \\ and Hari Mohan Srivastava ${ }^{6,7, *(D)}$ \\ 1 College of Business, Chung Yuan Christian University, Chung-Li 32023, Taiwan \\ 2 School of Business, National Taiwan University of Science and Technology, Taipei 10607, Taiwan \\ 3 Department of Business Administration, Chihlee University of Technology, Banqiao District, \\ New Taipei 22050, Taiwan \\ 4 Department of Applied Mathematics and Business Administration, Chung Yuan Christian University, \\ Chung-Li 32023, Taiwan \\ 5 Department of Applied Mathematics, Chung Yuan Christian University, Chung-Li 30323, Taiwan \\ 6 Department of Mathematics and Statistics, University of Victoria, Victoria, BC V8W 3R4, Canada \\ 7 Department of Medical Research, China Medical University Hospital, China Medical University, \\ Taichung 40402, Taiwan \\ * Correspondence: harimsri@math.uvic.ca; Tel.: +1-250-472-5313 or +1-250-477-6960
}

Received: 26 March 2019; Accepted: 27 June 2019; Published: 2 July 2019

\begin{abstract}
In the year 2004, Chang and Teng investigated an inventory model for deteriorating items in which the supplier not only provides a cash discount, but also allows a permissible delay in payments. The main purpose of the present investigation is three-fold, as follows. First, it is found herein that Theorem 1 of Chang and Teng (2004) has notable shortcomings in terms of their determination of the optimal solution of the annual total relevant cost $Z(T)$ by adopting the Taylor-series approximation method. Theorem 1 in this paper does not make use of the Taylor-series approximation method in order to overcome the shortcomings in Chang and Teng (2004) and alternatively derives all the optimal solutions of the annual total relevant cost $Z(T)$. Secondly, this paper systematically revisits the annual total relevant cost $Z(T)$ in Chang and Teng (2004) and presents in detail the mathematically correct ways for the derivations of $Z(T)$. Thirdly, this paper not only shows that Theorem 1 of Chang and Teng (2004) is not necessarily true for finding the optimal solution of the annual total relevant $\operatorname{cost} Z(T)$, but it also demonstrates how Theorem 1 in this paper can locate all of the optimal solutions of $Z(T)$. The mathematical analytic investigation presented in this paper is believed to be useful for correct managerial considerations and managerial decisions.
\end{abstract}

Keywords: inventory modelling and optimization; Trade-credit financing; Cash discounts; permissible delays in payments; Supply chain management; economic order quantity (EOQ); mathematical solution procedure; deteriorating items; mathematical analytic tools and techniques; managerial considerations and managerial decisions

JEL: Primary 91B24; 93C15; Secondary 90B30

\section{Introduction, Motivation and Preliminaries}

Recently, Stokes [1] mentioned that since trade credit arises spontaneously with a firm's purchases, it is understood to be one of the most flexible sources of short-term financing which is available to firms. From the viewpoint of important managerial considerations and managerial decisions, we need to include the idea to offer trade credit and the determination of the firm's terms of sale. Additionally, the decision of the purchasing firm to take (or not to take) any advantage of a cash discount and the 
motivations behind such a decision are also important in managerial considerations. By assuming the increasing salience of a sales promotion tool, Arcelus et al. [2] analyzed the advantages and disadvantages of the two most common payment reduction schemes. These schemes include a cash discount and a delay in the payment of the merchandise. Obviously, a cash discount can encourage the customer to pay cash upon the delivery and to reduce thereby the default risk. One may consider the permissible delay in payments as a kind of price reduction. Therefore, clearly, the permissible delay in payments will not only attract new customers for the firm, but it will also considerably increase the firm's sales.

Considering the importance of trade credit and several other features of the firm's cash-discount problem, Hill and Riener [3] considered a model for determining the cash discount in the firm's credit policy. Huang and Chung [4], on the other hand, studied the optimal replenishment and payment polices in the EOQ model under cash discount and trade credit. Huang [5] made an attempt to adopt the payment rule which was already discussed by Chung and Huang [6] as well as the policy of cash discount which was investigated by Huang and Chung [4] with a view to developing the buyer's inventory model. In fact, Chung [7] mentioned several shortcomings in the investigation by Huang [8] and presented the correct solution procedure for it. In addition, Ouyang et al. [9] studied an inventory model with the policy of non-instantaneous receipt under the cash discount and trade credit. Huang and Hsu [10] extended the work of Ouyang et al. [9] to hold true in a more general situation. Sana and Chaudhuri [11] modelled the retailer's profit-maximizing strategy in the situation when the retailer is confronted with the supplier's offer of trade credit and price discount on the purchase of a given merchandise. Finally, it was Ho et al. [12] who investigated and determined the optimal pricing, ordering, shipping, and payment policy with a view to maximizing the joint expected total profit per unit time under a two-part strategy, i.e., cash discount and delayed payment. Feng et al. [13] explored the retailer's optimal replenishment and payment policies in the economic production quantity (EPQ) model under the policy of cash discount as well as a two-level trade-credit policy. Yang [14] considered the optimal order and payment policies for deteriorating items in the analysis of discount cash flows under such alternatives as (for example) conditionally permissible delay in payments and cash discount. Quite recently, in an interesting paper, Taleizadeh et al. [15] considered the payment-delay policy in multi-product single-machine EPQ model with repair failure and back-ordering. Our above-detailed literature review reveals the fact that research about the inventory model under the cash-discount and trade-credit conditions still constitutes a popular topic in the study of operations and inventory management. The impact of deterioration in any given system is remarkably important. It is, therefore, necessary to manage the product's deterioration as, for instance, in fruit and vegetables which are known to deteriorate over time. Thus, for example, a model for exponentially decaying inventory was considered by Chare and Schrader [16], and Philip [17] discussed an inventory model with a three-parameter Weibull distribution rate and with no shortages. Later, Philip's aforementioned model in [17] was extended by Shah [18] who introduced shortages as well. We refer the reader to the remarkable survey by Aggarwal and Jaggi [19] dealing with some ordering policies of deteriorating items under permissible delay in payments. An order-level lot size inventory model with the inventory-level dependent demand and deterioration was discussed by Sarker et al. [20]. Liao et al. [21], on the other hand, studied an inventory model for deteriorating items under inflation and permissible delay in payments. Chang et al. [22] investigated and determined the optimal cycle time for deteriorating items under the policy of trade credit. The study by Arcelus et al. [2] included the retailer's pricing and trade-credit policy, as well as the inventory policies for deteriorating items. The work of Manna and Chaudhuri [23] presented an EOQ model involving the ramp-type demand rate, the time-dependent deterioration rate, the unit production cost, as well as shortages. In the existing literature on the subject of our present investigation, one can find papers which are related to variable deterioration such as those by Sana and Chaudhary [11], Skouri et al. [24], Sett et al. [25], Sarkar [26], Sarkar and Sarkar [27] and Sarker et al. [20]. Other related recent developments on the subject-matter of this article can be found in the works by (for example) Chung et al. (see [6,7,28-31]), 
Feng et al. [13], Hill and Riener [3], Ho et al. [12], Huang et al. (see [4,5,10]), Liao et al. (see [21,32,33]), and Srivastava et al. [34].

It should be remarked that Sarkar and Sarkar [27] studied a significantly improved inventory model involving what may be referred to probabilistic deterioration. Their solution of the model depended heavily upon Control Theory. On the other hand, Sarkar et al. [35] considered an EOQ model for deteriorating items together with time-dependent increasing demand. They found the component cost as well as the selling price as a continuous time-rate. Sarkar and Sarkar [27] also considered an inventory model involving infinite replenishment rate, stock-dependent demand, time-varying deterioration rates as well as partial backlogging. A production-inventory model involving probabilistic deterioration in two-echelon supply chain was discussed by Sarkar [26]. Derivation of the marketing policy for non-instantaneous deteriorating items involving a generalized-type deterioration and holding-cost rates can indeed be found in the investigation by Shah et al. [18]. Chung et al. [28] considered inventory modelling involving non-instantaneous receipt and exponentially deteriorating items in the case of an integrated three-layer supply chain system under two-level trade-credit. A discussion in the case of several lot-sizing policies for deterioration items under two-level trade credit with partial trade credit to credit-risk retailer and limited storage capacity can be seen in the work by Liao et al. [33]. Wu et al. [36] presented inventory-related policies for perishable products with expiration dates and advance-cash-credit payment schemes. By making use of the Stackelberg and the Nash equilibrium solution, Jaggi et al. [37] explored inventory and credit decisions in the case of deteriorating items with displayed stock-dependent demand involving the two-echelon supply chain. Many other remarkable studies about deteriorating items can be found in the article by Kawale and Sanas [38] (see also [39,40]).

By combining all elements of the trade credit, the cash discount and the deteriorating items, Chang and Teng [41] studied a certain inventory model for deteriorating items in the case when the supplier does not only provide a cash discount, but also allows a permissible delay in payments. We remark in passing that a cash discount can encourage the customer to pay on delivery and it can also reduce the default risk. In the past few years, marketing researchers and practitioners in the area of supply chain management appear to have recognized and understood the phenomenon that the supplier offers a permissible delay in payment to the retailer if the outstanding amount is paid within the permitted fixed settlement period, known as the trade-credit period. During the trade-credit period, the retailer is allowed to accumulate revenues received upon selling items and earning interests. Consequently, without any incentive to make early payments and with the possibility and prospect of earning interest by means of the accumulated revenue which is received during the credit period, the retailer chooses to postpone payment until the last moment of the permissible period which is allowed by the supplier. Thus, clearly, the offer of the trade credit does lead to delayed cash inflow and to thereby increase the risk of cash-flow shortage as well as bad debt. From the suppliers' viewpoint, it is always hoped that they will be able to find a trade-credit policy to increase sales and to decrease the risk of cash-flow shortage and bad debt. In reality, however, especially on the side of the operations management, a supplier is generally willing and ready to provide the retailer with either a cash discount or a permissible delay in payments or both.

The main purpose of the present investigation is three-fold as stated below.

1 To observe that Theorem 1 of Chang and Teng [41] has notable shortcomings in their determination of the optimal solution of the annual total relevant cost $Z(T)$ by adopting the Taylor-series approximation method. Theorem 1 in this paper does not make use of the Taylor-series approximation method in order to overcome the shortcomings in Chang and Teng [41] and thereby derive the optimal solutions of the annual total relevant $\operatorname{cost} Z(T)$.

2 To systematically revisit the annual total relevant cost $Z(T)$ in Chang and Teng [41] and to present in detail the mathematically correct ways for the derivations of $Z(T)$.

3 To not only show that Theorem 1 of Chang and Teng [41] is not necessarily true for finding the optimal solution of the annual total relevant $\operatorname{cost} Z(T)$, but to also demonstrate how Theorem 1 in this paper can locate all of the optimal solutions of $Z(T)$. 
The mathematically correct analytic investigation of the model, which we have presented in this paper, is believed to be useful for correct managerial considerations and right managerial decisions (see also [41]).

\section{The Mathematical Modelling of the Problem}

This paper adopts the same assumptions and notations as described in Chang and Teng [41].

\section{Assumptions}

(1) The demand for the item is constant with time.

(2) Shortages are not allowed.

(3) Replenishment is instantaneous.

(4) During the time the account is not settled, generated sales revenue is deposited in an interest-bearing account. At the end of this period (that is, $M_{1}$ or $M_{2}$ ), the customer pays the supplier the total amount in the interest-bearing account, and then starts paying off the amount owed to the supplier whenever the customer has money obtained from sales.

(5) Time horizon is infinite.

\section{Notations}

$D=$ the demand rate per year.

$h=$ the unit holding cost per year excluding interest charges.

$p=$ the selling price per unit.

$c=$ the unit purchasing cost, with $c<p$.

$I_{c}=$ the interest charged per $\$$ in stocks per year by the supplier or a bank.

$I_{d}=$ the interest earned per $\$$ per year.

$S=$ the ordering cost per order.

$r=$ the cash discount rate, $0<r<1$.

$\theta=$ the constant deterioration rate, where $0 \leq \theta<1$.

$M_{1}=$ the period of cash discount.

$M_{2}=$ the period of permissible delay in settling account, with $M_{2}>M_{1}$.

$T=$ the replenishment time interval.

$I(t)=\frac{D}{\theta}\left[e^{\theta(T-t)}-1\right]$, where $0 \leq t \leq T$.

Policy I: The customer accepts the cash discount and makes the full payment at time $M_{1}$.

Policy II: The customer does not accept the cash discount and makes the full payment at time $M_{2}$.

$\mathrm{TVC}_{1}(T)=$ the annual total relevant cost when the customer adopts Policy (I).

$\mathrm{TVC}_{2}(T)=$ the annual total relevant cost when the customer adopts Policy (II).

$T_{1}^{*}=$ the optimal replenishment time of $\operatorname{TVC}_{1}(T)$.

$T_{2}^{*}=$ the optimal replenishment time of $\mathrm{TVC}_{2}(T)$.

$Z(T)=$ the annual total relevant cost

$$
= \begin{cases}\operatorname{TVC}_{1}(T) & \text { if the customer adopts Policy I } \\ \operatorname{TVC}_{2}(T) & \text { if the customer adopts Policy II. }\end{cases}
$$

$T^{*}=$ the optimal replenishment time of $Z(T)$.

$$
\overline{W_{1}}=\frac{\ln \left(\frac{p \theta M_{1}+p I_{d} \theta M_{1}^{2}}{c(1-r)}+1\right)}{\ln \left(\frac{p \theta M_{2}+\frac{p I_{d} \theta M_{2}^{2}}{2}}{c}+1\right)}
$$


The annual total relevant $\operatorname{cost} Z(T)$ consists of the following items:

(a) The cost of placing order;

(b) The cost of purchasing units;

(c) The cost of carrying inventory (excluding interest changes);

(d) The cost discount earned;

(e) The interest earned from sales revenue during the permissible period $\left[0, M_{1}\right]$ or $\left[0, M_{2}\right]$

(f) The cost of interest change for unsold items after the permissible delay $M_{1}$ or $M_{2}$.

Therefore, we have

$$
\text { the annual total relevant cost }=(a)+(b)+(c)-(d)-(e)+(f)
$$

Chang and Teng [41] reveal that

$$
\begin{gathered}
\text { (a) Cost of placing order }=\frac{S}{T}, \\
\text { (b) Cost of purchasing units }=\frac{c D}{\theta T}\left(e^{\theta T}-1\right), \\
\text { (c) Cost of carrying inventory }=\frac{h D}{\theta^{2} T}\left(e^{\theta T}-1\right)-\frac{h D}{\theta}, \\
\text { (d) Cash discount earned }= \begin{cases}\frac{r c D}{\theta T}\left(e^{\theta T}-1\right) & \text { if Policy I is adopted; } \\
0 & \text { if Policy II is adopted. }\end{cases}
\end{gathered}
$$

Regarding the interest charged and earned, the following four possible cases, which are based upon the customer's two choices (Policy I and Policy II), occur:

Case I. The customers adopt Policy (I) and $\overline{W_{1}}>M_{1}$

(A) $T>M_{1}$

Chang and Teng [41] showed that

(e)

$$
\text { The interest earned per year }=\frac{p I_{d} D M_{1}^{2}}{2 T}
$$

(f) The internet payable per year

The customer buys $I(0)$ units at time 0 , and owes $c(1-r) I(0)$ to the supplier. At the time $M_{1}$, the customer sells $D M_{1}$ units in total, and has $p D M_{1}$ plus the interest earned $\frac{p I_{d} D M_{1}^{2}}{2}$ to pay the supplier. From the difference between the total purchase cost $c(1-r) I(0)$ and the total amount of money in the account, i.e.,

$$
p D M_{1}+\frac{p I_{d} D M_{1}^{2}}{2}
$$

the following two cases to occur:

(i) If

$$
p D M_{1}+\frac{p I_{d} D M_{1}^{2}}{2}>c(1-r) I(0),
$$

Equation (3) in Chang and Teng [41] implies that

$$
\overline{W_{1}}=\frac{\ln \left(\frac{p \theta M_{1}+p I_{d} \theta M_{1}^{2}}{c(1-r)}+1\right)}{\theta}>T \geq M_{1}
$$

and 
From Equations (2) to (9), the annual total relevant cost $Z_{5}(T)$ is given by

$$
\begin{array}{r}
Z_{5}(T)=\frac{S}{T}+\frac{D[h+c \theta(1-r)]}{\theta^{2} T}\left(e^{\theta T}-1\right) \\
-\frac{h D}{\theta}-\frac{p I_{d} D M_{1}^{2}}{2 T} \text { if } M_{1} \leq T<\overline{W_{1}} .
\end{array}
$$

(ii) If

$$
p D M_{1}+\frac{p I_{d} D M_{1}^{2}}{2} \leq c(1-r) I(0),
$$

we have $T \geq \overline{W_{1}}$. Chang and Teng [41] demonstrated that

the interest payable per year

$$
=\frac{I_{c}}{2 p D T}\left[\frac{c(1-r) D}{\theta}\left(e^{\theta T}-1\right)-p D M_{1}\left(1+\frac{I_{d} M_{1}}{2}\right)\right]^{2} .
$$

From Equations (2) to (6) and (10) to (12), we find the annual total relevant cost $Z_{1}(T)$ given by

$$
\begin{aligned}
Z_{1}(T)= & \frac{S}{T}+\frac{D[h+c \theta(1-r)]}{\theta^{2} T}\left(e^{\theta T}-1\right)-\frac{h D}{\theta}-\frac{p I_{d} D M_{1}^{2}}{2 T} \\
& +\frac{I_{c}}{2 p D T}\left[\frac{c(1-r) D}{\theta}\left(e^{\theta T}-1\right)-p D M_{1}\left(1+\frac{I_{d} M_{1}}{2}\right)\right]^{2} \\
& \text { if } \quad T \geq \overline{W_{1}} .
\end{aligned}
$$

(B) $T \leq M_{1}$

Under Case I (B), the customer sells DT units in total at time $T$, and has $c D T$ to pay the supplier in full at time $M_{1}$. Therefore, Chang and Teng [41] derived the annual total relevant cost $Z_{2}(T)$ as follows:

$$
\begin{aligned}
& Z_{2}(T)=\frac{S}{T}+\frac{D[h+c \theta(1-r)]}{\theta^{2} T}\left(e^{\theta T}-1\right) \\
& -\frac{h D}{\theta}-p I_{d} D\left(M_{1}-\frac{T}{2}\right) \text { if } 0<T<M_{1}
\end{aligned}
$$

Combining Case I (A) and Case I (B), we have

$$
\operatorname{TVC}_{1}(T)= \begin{cases}Z_{2}(T) & \text { if } \quad 0<T \leq M_{1} \\ Z_{5}(T) & \text { if } \quad M_{1}<T<\overline{W_{1}} \\ Z_{1}(T) & \text { if } \quad T \geq \overline{W_{1}}\end{cases}
$$

Since

$$
Z_{2}\left(M_{1}\right)=Z_{5}\left(M_{1}\right) \quad \text { and } \quad Z_{5}\left(\overline{W_{1}}\right)=Z_{1}\left(\overline{W_{1}}\right),
$$

the function $\operatorname{TVC}_{1}(T)$ is continuous when $T>0$ if $\overline{W_{1}}>M_{1}$. For convenience, all the items $Z_{2}(T)$, $Z_{5}(T)$ and $Z_{1}(T)$ are defined on $T>0$. Case 1 in Chang and Teng [41] only discussed Equation (11) and ignored Equation (7) of this paper. When Equation (11) of this paper holds true, then Equation (3) in Chang and Teng [41] implies that

$$
T \geq \overline{W_{1}}>M_{1}
$$

Case I (B) and Equation (16) reveal that the domain of the function $\operatorname{TVC}_{1}(T)$ is the set given by $\left(0, M_{1}\right] \cup\left[\overline{W_{1}}, \infty\right)$, but not the set $(0, \infty)$. The interval $\left(M_{1}, \overline{W_{1}}\right)$ is not contained in the domain of the function $\operatorname{TVC}_{1}(T)$. Therefore, the annual total relevant cost of Cases 1 and 2 in Chang and Teng [41] can be expressed as follows: 


$$
\operatorname{TVC}_{1}(T)= \begin{cases}Z_{2}(T) & \text { if } \quad 0<T \leq M_{1} \\ Z_{1}(T) & \text { if } \quad T \geq \overline{W_{1}} .\end{cases}
$$

The functional behavior of $\mathrm{TVC}_{1}(T)$ on the interval $\left(M_{1}, \overline{W_{1}}\right)$ was not discussed in Chang and Teng [41]. This does not make sense, since the domain of $\operatorname{TVC}_{1}(T)$ should be $(0, \infty)$. The correct derivation of $\operatorname{TVC}_{1}(T)$ should consider Equations (7) and (11) together. Consequently, it is the shortcoming of the modelling of Chang and Teng [41]. Equations (15a), (15b) and (15c) correct the claims made by Chang and Teng [41].

Case II. The customer adopts Policy I and $\overline{W_{1}} \leq M_{1}$

(C) $T>M_{1}$

If $T \geq M_{1} \geq \overline{W_{1}}$, then Equation (11) holds true. Following the same arguments as in Case I (A) (ii), we find that

the interest payable per year

$$
=\frac{I_{c}}{2 p D T}\left[\frac{c(1-r) D}{\theta}\left(e^{\theta T}-1\right)-p D M_{1}\left(1+\frac{I_{d} M_{1}}{2}\right)\right]^{2} .
$$

According to Equations (2) to (6) and (17), the annual total relevant cost $\mathrm{TVC}_{1}(T)$ can be expressed as follows:

$$
\operatorname{TVC}_{1}(T)= \begin{cases}Z_{2}(T) & \text { if } \quad 0<T \leq M_{1} \\ Z_{1}(T) & \text { if } \quad M_{1}<T\end{cases}
$$

Since $Z_{2}\left(M_{1}\right)<Z_{1}\left(M_{1}\right)$, the function $\operatorname{TVC}_{1}(T)$ is continuous except when $T=M_{1}$ if $M_{1} \geq \overline{W_{1}}$.

Case III. The customer adopts Policy II and $\overline{W_{3}}>M_{2}$

Following the same arguments as in Case I, the annual total relevant cost $\mathrm{TVC}_{2}(T)$ can be expressed as follows:

$$
\operatorname{TVC}_{2}(T)= \begin{cases}Z_{4}(T) & \text { if } \quad 0<T \leq M_{2} \\ Z_{6}(T) & \text { if } \quad M_{2}<T<\overline{W_{3}} \\ Z_{3}(T) & \text { if } \quad T \geq \overline{W_{3}}\end{cases}
$$

where

$$
\begin{gathered}
Z_{4}(T)=\frac{S}{T}+\frac{D(h+c \theta)}{\theta^{2} T}\left(e^{\theta T}-1\right)-\frac{h D}{\theta}-p I_{d} D\left(M_{2}-\frac{T}{2}\right), \\
Z_{6}(T)=\frac{S}{T}+\frac{D(h+c \theta)}{\theta^{2} T}\left(e^{\theta T}-1\right)-\frac{h D}{\theta}-\frac{p I_{d} D M_{2}^{2}}{2 T}, \\
Z_{3}(T)=\frac{S}{T}+\frac{D(h+c \theta)}{\theta^{2} T}\left(e^{\theta T}-1\right)-\frac{h D}{\theta}-\frac{p I_{d} D M_{2}^{2}}{2 T} \\
+\frac{I_{c}}{2 p D T}\left[\frac{c D}{\theta}\left(e^{\theta T}-1\right)-p D M_{2}\left(1+\frac{I_{d} M_{2}}{2}\right)\right]^{2}
\end{gathered}
$$

and

$$
\overline{W_{3}}=\frac{\ln \left(\frac{\left.p \theta M_{2}+\frac{p I_{d} \theta M_{2}^{2}}{2}+1\right)}{c} .\right.}{\theta} .
$$


Since

$$
Z_{4}\left(M_{2}\right)=Z_{6}\left(M_{2}\right) \quad \text { and } \quad Z_{6}\left(\overline{W_{3}}\right)=Z_{3}\left(\overline{W_{3}}\right),
$$

the function $\mathrm{TVC}_{2}(T)$ is continuous when $T>0$ if $M_{2}<\overline{W_{3}}$. For convenience, all the items $Z_{4}(T)$, $Z_{6}(T)$ and $Z_{3}(T)$ are defined on $T>0$. Let us now use the inequalities given by Equations (24) and (25) as follows:

$$
p D M_{2}+\frac{p I_{d} D M_{2}^{2}}{2}>c I(0)
$$

and

$$
p D M_{2}+\frac{p I_{d} D M_{2}^{2}}{2} \leq c I(0),
$$

respectively. Case 3 in Chang and Teng [41] only discussed Equation (25) and ignored Equation (24) above. When Equation (25) in this paper holds true, Equation (3) in Chang and Teng [41] implies that

$$
T \geq \overline{W_{3}}>M_{2} .
$$

Case II (D) and Equation (26) reveal that the domain of the function $\mathrm{TVC}_{2}(T)$ is the set $\left(0, M_{2}\right] \cup$ $\left[\overline{W_{3}}, \infty\right)$, but not the set $(0, \infty)$. The interval $\left(M_{2}, \overline{W_{3}}\right)$ is not contained in the domain of the function $\mathrm{TVC}_{2}(T)$. Therefore, the annual total relevant cost of Cases 3 and 4 in Chang and Teng [41] can be expressed as follows:

$$
\operatorname{TVC}_{2}(T)= \begin{cases}Z_{4}(T) & \text { if } \quad 0<T \leq M_{2} \\ Z_{3}(T) & \text { if } \quad T \geq \overline{W_{3}}\end{cases}
$$

The functional behavior of $\mathrm{TVC}_{2}(T)$ on $\left(\mathrm{M}_{2}, \overline{\mathrm{W}_{3}}\right)$ was not discussed in Chang and Teng [41]. This exclusion does not make sense, since the domain of $\operatorname{TVC}_{2}(T)$ should be $(0, \infty)$. The correct derivation of $\mathrm{TVC}_{2}(T)$ should, in fact, consider the equations (24) and (25) together. Consequently, it is another shortcoming of the modelling by Chang and Teng [41]. Equations (19a), (19b) and (19c) correct the claims by Chang and Teng [41].

Case IV. The customer adopts Policy II and $\overline{W_{3}} \leq M_{2}$.

Following the same arguments as in Case II, the annual total relevant cost $\mathrm{TVC}_{2}(T)$ can be expressed as follows:

$$
\operatorname{TVC}_{2}(T)=\left\{\begin{array}{lll}
Z_{4}(T) & \text { if } & 0<T \leq M_{2} \\
Z_{3}(T) & \text { if } & M_{2}<T
\end{array}\right.
$$

Since $Z_{4}\left(M_{2}\right)<Z_{3}\left(M_{2}\right)$, the function $\operatorname{TVC}_{2}(T)$ is continuous except when $T=M_{2}$ if $M_{2} \geq \overline{W_{3}}$. Upon combining Cases I to IV, the annual total relevant cost $Z(T)$ can be expressed as follows:

$$
Z(T)= \begin{cases}\mathrm{TVC}_{1}(T) & \text { if the customer adopts Policy I; } \\ \mathrm{TVC}_{2}(T) & \text { if the customer adopts Policy II. }\end{cases}
$$

The objective here is to determine which policy [ $T_{1}^{*}$ (Policy I) or $T_{2}^{*}$ (Policy II)] satisfies the following condition:

$$
Z\left(T^{*}\right)=\min \left\{\operatorname{TVC}_{1}\left(T_{1}^{*}\right), \operatorname{TVC}_{2}\left(T_{2}^{*}\right)\right\}
$$




\section{The Convexity of $Z_{i}(T)$}

By making use of Equations (10), (13), (14), (20), (21) and (22), we find for the first and the second derivatives of the annual total relevant $\operatorname{cost} Z_{2}(T)$ that

$$
\begin{aligned}
& Z_{2}^{\prime}(T)=-\frac{S}{T^{2}}+\frac{D[h+c \theta(1-r)]}{\theta^{2} T^{2}}\left(\theta T e^{\theta T}-e^{\theta T}+1\right)+\frac{p I_{d} D}{2}, \\
& Z_{2}^{\prime \prime}(T)=\frac{2 S}{T^{3}}+\frac{2 D[h+c \theta(1-r)]}{\theta^{2} T^{3}}\left(e^{\theta T}-1-\theta T e^{\theta T}+\frac{1}{2} \theta^{2} T^{2} e^{\theta T}\right), \\
& Z_{5}^{\prime}(T)=-\frac{S}{T^{2}}+\frac{D[h+c \theta(1-r)]}{\theta^{2} T^{2}}\left(\theta T e^{\theta T}-e^{\theta T}+1\right)+\frac{p I_{d} D M_{1}^{2}}{2 T^{2}}, \\
& Z_{5}^{\prime \prime}(T)=\frac{2 S-p I_{d} D M_{1}^{2}}{T^{3}}+\frac{D[h+c \theta(1-r)]}{\theta^{2} T^{3}}\left(e^{\theta T}-1-\theta T e^{\theta T}+\frac{1}{2} \theta^{2} T^{2} e^{\theta T}\right), \\
& Z_{1}^{\prime}(T)=-\frac{S}{T^{2}}+\frac{D h+B_{1} \theta^{2}}{\theta^{2} T^{2}}\left(\theta T e^{\theta T}-e^{\theta T}+1\right)+\frac{p I_{d} D M_{1}^{2}}{2 T^{2}} \\
& +\frac{I_{\mathcal{C}}}{2 p D T^{2}}\left(2 B_{1}^{2} \theta T e^{2 \theta T}-B_{1}^{2} e^{2 \theta T}-2 B_{1} W_{1} \theta T e^{\theta T}+2 B_{1} W_{1} e^{\theta T}-W_{1}^{2}\right), \\
& Z_{1}^{\prime \prime}(T)=\frac{2 S}{T^{3}}+\frac{2\left(D h+B_{1} \theta^{2}\right)}{\theta^{2} T^{3}}\left(e^{\theta T}-1-\theta T e^{\theta T}+\frac{1}{2} \theta^{2} T^{2} e^{\theta T}\right)-\frac{p I_{d} D M_{1}^{2}}{T^{3}} \\
& +\frac{I_{c}}{2 p D T^{3}}\left[4 B_{1}^{2}(\theta T)^{2} e^{2 \theta T}-4 B_{1}^{2} \theta T e^{2 \theta T}+2 B_{1}^{2} e^{2 \theta T}-2 B_{1} W_{1}(\theta T)^{2} e^{\theta T}\right. \\
& \left.+4 B_{1} W_{1} \theta T e^{\theta T}-4 B_{1} W_{1} e^{\theta T}+2 W_{1}^{2}\right], \\
& Z_{4}^{\prime}(T)=-\frac{S}{T^{2}}+\frac{D[h+c \theta]}{\theta^{2} T^{2}}\left(\theta T e^{\theta T}-e^{\theta T}+1\right)+\frac{p I_{d} D}{2}, \\
& Z_{4}^{\prime \prime}(T)=\frac{2 S}{T^{3}}+\frac{2 D[h+c \theta]}{\theta^{2} T^{3}}\left(e^{\theta T}-1-\theta T e^{\theta T}+\frac{1}{2} \theta^{2} T^{2} e^{\theta T}\right), \\
& Z_{6}^{\prime}(T)=-\frac{S}{T^{2}}+\frac{D[h+c \theta]}{\theta^{2} T^{2}}\left(\theta T e^{\theta T}-e^{\theta T}+1\right)+\frac{p I_{d} D M_{2}^{2}}{2 T^{2}}, \\
& Z_{6}^{\prime \prime}(T)=\frac{2 S-p I_{d} D M_{2}^{2}}{T^{3}}+\frac{D[h+c \theta]}{\theta^{2} T^{3}}\left(e^{\theta T}-1-\theta T e^{\theta T}+\frac{1}{2} \theta^{2} T^{2} e^{\theta T}\right), \\
& Z_{3}^{\prime}(T)=-\frac{S}{T^{2}}+\frac{D h+B_{3} \theta^{2}}{\theta^{2} T^{2}}\left(\theta T e^{\theta T}-e^{\theta T}+1\right)+\frac{p I_{d} D M_{2}^{2}}{2 T^{2}} \\
& +\frac{I_{\mathcal{C}}}{2 p D T^{2}}\left(2 B_{3}^{2} \theta T e^{2 \theta T}-B_{3}^{2} e^{2 \theta T}-2 B_{3} W_{3} \theta T e^{\theta T}+2 B_{3} W_{3} e^{\theta T}-W_{3}^{2}\right)
\end{aligned}
$$

and

$$
\begin{aligned}
Z_{3}^{\prime \prime}(T)= & \frac{2 S}{T^{3}}+\frac{2\left(D h+B_{3} \theta^{2}\right)}{\theta^{2} T^{3}}\left(e^{\theta T}-1-\theta T e^{\theta T}+\frac{1}{2} \theta^{2} T^{2} e^{\theta T}\right)-\frac{p I_{d} D M_{2}^{2}}{T^{3}} \\
& +\frac{I_{c}}{2 p D T^{3}}\left[4 B_{3}^{2}(\theta T)^{2} e^{2 \theta T}-4 B_{3}^{2} \theta T e^{2 \theta T}+2 B_{3}^{2} e^{2 \theta T}-2 B_{3} W_{3}(\theta T)^{2} e^{\theta T}\right. \\
& \left.+4 B_{3} W_{3} \theta T e^{\theta T}-4 B_{3} W_{3} e^{\theta T}+2 W_{3}^{2}\right]
\end{aligned}
$$


where

$$
\begin{gathered}
A_{1}=p D M_{1}\left(1+\frac{I_{d} M_{1}}{2}\right) \quad \text { and } \quad B_{1}=\frac{c(1-r) D}{\theta}, \\
A_{3}=p D M_{2}\left(1+\frac{I_{d} M_{2}}{2}\right) \quad \text { and } \quad B_{3}=\frac{c D}{\theta}
\end{gathered}
$$

and

$$
W_{1}=A_{1}+B_{1} \quad \text { and } \quad W_{3}=A_{3}+B_{3} .
$$

We now suppose that

$$
G=2 S-p I_{d} D M_{2}^{2}
$$

Then, clearly, we have the results asserted by Theorem 1 below.

Theorem 1. Each of the following assertions holds true:
(A) $e^{\theta T}-1-\theta T e^{\theta T}+\frac{1}{2} \theta^{2} T^{2} e^{\theta T}>0$ if $T>0$.
(B) (i) $\theta T e^{\theta T}-e^{\theta T}+1$ is increasing if $T>0$.
(ii) $\theta T e^{\theta T}-e^{\theta T}+1>\frac{\theta^{2} T^{2}}{2}$ if $T>0$.
(C) $2 B_{1}^{2} \theta T e^{2 \theta T}-B_{1}^{2} e^{2 \theta T}-2 B_{1} W_{1} \theta T e^{\theta T}+2 B_{1} W_{1} e^{\theta T}-W_{1}^{2} \geq 0$ if $T \geq \overline{W_{1}}$
(D) $2 B_{3}^{2} \theta T e^{2 \theta T}-B_{3}^{2} e^{2 \theta T}-2 B_{3} W_{3} \theta T e^{\theta T}+2 B_{3} W_{3} e^{\theta T}-W_{3}^{2} \geq 0$ if $T \geq \overline{W_{3}}$
(E) Both $Z_{2}(T)$ and $Z_{4}(T)$ are convex on $T>0$.
(F) If $G>0$, then both $Z_{5}(T)$ and $Z_{6}(T)$ are convex on $T>0$.
(G) If $3 B_{1}>A_{1}$, then $Z_{1}(T)$ are convex on $T>0$.
(H) If $3 B_{3}>A_{3}$, then $Z_{3}(T)$ are convex on $T>0$.

\section{Proof.}

(A) See Lemma 1 in Huang and Liao [8].

(B) Let

$$
f(x)=x e^{x}-e^{x}+1
$$

and

$$
k(x)=x e^{x}-e^{x}+1-\frac{x^{2}}{2} .
$$

Equations (43) and (44) yield

$$
f^{\prime}(x)=x e^{x}>0 \text { if } x>0
$$

and

$$
k^{\prime}(x)=x\left(e^{x}-1\right)>0 \text { if } x>0 .
$$

Equations (45) and (46) imply that both functions $f(x)$ and $k(x)$ are increasing when $x>0$. Therefore, we get

$$
f(x)>f(0)=0 \quad \text { and } \quad k(x)>k(0)=0 .
$$

We now set $x=\theta T$. Consequently, we have

(i) $\theta T e^{\theta T}-e^{\theta T}+1$ is increasing if $T>0$.

(ii) $\quad \theta T e^{\theta T}-e^{\theta T}+1>\frac{\theta^{2} T^{2}}{2}$ if $T>0$.

(C) Let

$$
g(T)=2 B_{1}^{2} \theta T e^{2 \theta T}-B_{1}^{2} e^{2 \theta T}-2 B_{1} W_{1} \theta T e^{\theta T}+2 B_{1} W_{1} e^{\theta T}-W_{1}^{2}
$$


Then

$$
g^{\prime}(T)=2 \theta^{2} T B_{1}^{2} e^{\theta T}\left(2 e^{\theta T}-\frac{W_{1}}{B_{1}}\right)
$$

So, we have

$$
g^{\prime}(T)>0 \text { if } T \geq \overline{W_{1}} .
$$

Equation (47) implies that the function $g(T)$ is increasing if $T \geq \overline{W_{1}}$. Therefore, we have

$$
g(T)>g\left(\overline{W_{1}}\right)=0 \text { if } T \geq \overline{W_{1}}
$$

Consequently, we obtain

$$
2 B_{1}^{2} \theta T e^{2 \theta T}-B_{1}^{2} e^{2 \theta T}-2 B_{1} W_{1} \theta T e^{\theta T}+2 B_{1} W_{1} e^{\theta T}-W_{1}^{2} \geq 0
$$

if $T \geq \overline{W_{1}}$.

(D) The proof is similar to that of Theorem 1 (C).

(E) Equations (31), (37) and Theorem 1 (A) imply that $Z_{2}^{\prime \prime}(T)>0$ and $Z_{4}^{\prime \prime}(T)>0$. Therefore, both functions $Z_{2}(T)$ and $Z_{4}(T)$ are convex on $T>0$.

(F) If $G>0$, then $2 S-p I_{d} D M_{1}^{2} \geq G>0$. Equations (33) and (39) imply that $Z_{5}^{\prime \prime}(T)>0$ and $Z_{6}^{\prime \prime}(T)>0$. Therefore, both functions $Z_{5}(T)$ and $Z_{6}(T)$ are convex when $T>0$ if $G>0$.

(G) See, for details, Lemma 2 in the paper by Huang and Liao [8].

(H) See, for details, Lemma 2 in the paper by Huang and Liao [8].

\section{Theorems for the Optimal Cycle $T^{*}$ of $Z(T)$}

Equations (30), (32), (34), (36), (38) and (40) yield

$$
\begin{aligned}
Z_{2}^{\prime}\left(M_{1}\right)= & Z_{5}^{\prime}\left(M_{1}\right) \\
= & \frac{1}{\theta^{2} M_{1}^{2}}\left\{-S \theta^{2}+D[h+c \theta(1-r)]\left(\theta M_{1} e^{\theta M_{1}}-e^{\theta M_{1}}+1\right)+\frac{p I_{d} D \theta^{2} M_{1}^{2}}{2}\right\}, \\
Z_{5}^{\prime}\left(\overline{W_{1}}\right)= & Z_{1}^{\prime}\left(\overline{W_{1}}\right) \\
= & \frac{1}{\theta^{2}{\overline{W_{1}}}^{2}}\left\{-S \theta^{2}+D[h+c \theta(1-r)]\left(\theta \overline{W_{1}} e^{\theta \overline{W_{1}}}-e^{\theta \overline{W_{1}}}+1\right)+\frac{p I_{d} D \theta^{2} M_{1}^{2}}{2}\right\}, \\
Z_{1}^{\prime}\left(M_{1}\right)= & \frac{1}{\theta^{2} M_{1}^{2}}\left\{-S \theta^{2}+D[h+c \theta(1-r)]\left(\theta M_{1} e^{\theta M_{1}}-e^{\theta M_{1}}+1\right)+\frac{p I_{d} D \theta^{2} M_{1}^{2}}{2}\right. \\
& \left.+\frac{I_{c} \theta^{2}}{2 p D}\left[2 B_{1}^{2} \theta M_{1} e^{2 \theta M_{1}}-B_{1}^{2} e^{2 \theta M_{1}}-2 B_{1} W_{1} \theta M_{1} e^{\theta M_{1}}+2 B_{1} W_{1} e^{\theta M_{1}}-W_{1}^{2}\right]\right\},
\end{aligned}
$$




$$
\begin{aligned}
Z_{4}^{\prime}\left(M_{2}\right) & =Z_{6}^{\prime}\left(M_{2}\right) \\
& =\frac{1}{\theta^{2} M_{2}^{2}}\left\{-S \theta^{2}+D(h+c \theta)\left(\theta M_{2} e^{\theta M_{2}}-e^{\theta M_{2}}+1\right)+\frac{p I_{d} D \theta^{2} M_{2}^{2}}{2}\right\}, \\
Z_{6}^{\prime}\left(\overline{W_{3}}\right) & =Z_{3}^{\prime}\left(\overline{W_{3}}\right) \\
& =\frac{1}{\theta^{2}{\overline{W_{3}}}^{2}}\left\{-S \theta^{2}+D(h+c \theta)\left(\theta \overline{W_{3}} e^{\theta \overline{W_{3}}}-e^{\theta \overline{W_{3}}}+1\right)+\frac{p I_{d} D \theta^{2} M_{2}^{2}}{2}\right\}
\end{aligned}
$$

and

$$
\begin{aligned}
Z_{3}^{\prime}\left(M_{2}\right)= & \frac{1}{\theta^{2} M_{2}^{2}}\left\{-S \theta^{2}+D(h+c \theta)\left(\theta M_{2} e^{\theta M_{2}}-e^{\theta M_{2}}+1\right)+\frac{p I_{d} D \theta^{2} M_{2}^{2}}{2}\right. \\
& \left.+\frac{I_{c} \theta^{2}}{2 p D}\left[2 B_{3}^{2} \theta M_{2} e^{2 \theta M_{2}}-B_{3}^{2} e^{2 \theta M_{2}}-2 B_{3} W_{3} \theta M_{2} e^{\theta M_{2}}+2 B_{3} W_{3} e^{\theta M_{2}}-W_{3}^{2}\right]\right\} .
\end{aligned}
$$

Case I. Policy I is adopted and $M_{1}<\overline{W_{1}}$.

Let

$$
\begin{aligned}
\triangle_{25} & =\theta^{2} M_{1}^{2} Z_{2}^{\prime}\left(M_{1}\right)=\theta^{2} M_{1}^{2} Z_{5}^{\prime}\left(M_{1}\right) \\
& =-S \theta^{2}+D[h+c \theta(1-r)]\left(\theta M_{1} e^{\theta M_{1}}-e^{\theta M_{1}}+1\right)+\frac{p I_{d} D \theta^{2} M_{1}^{2}}{2}
\end{aligned}
$$

and

$$
\begin{aligned}
\triangle_{51} & =\theta^{2}\left(\overline{W_{1}}\right)^{2} Z_{5}^{\prime}\left(\overline{W_{1}}\right)=\theta^{2}\left(\overline{W_{1}}\right)^{2} Z_{1}^{\prime}\left(\overline{W_{1}}\right) \\
& =-S \theta^{2}+D[h+c \theta(1-r)]\left(\theta \overline{W_{1}} e^{\theta \overline{W_{1}}}-e^{\theta \overline{W_{1}}}+1\right)+\frac{p I_{d} D \theta^{2} M_{1}^{2}}{2} .
\end{aligned}
$$

Since $M_{1}<\overline{W_{1}}$, Theorem 1 (B) implies that

$$
\triangle_{51}>\triangle_{25}
$$

Case II. Policy I is adopted and $M_{1} \geq \overline{W_{1}}$.

Let

$$
\begin{aligned}
\triangle_{2} & =\theta^{2} M_{1}^{2} Z_{2}^{\prime}\left(M_{1}\right) \\
& =-S \theta^{2}+D[h+c \theta(1-r)]\left(\theta M_{1} e^{\theta M_{1}}-e^{\theta M_{1}}+1\right)+\frac{p I_{d} D \theta^{2} M_{1}^{2}}{2}
\end{aligned}
$$


and

$$
\begin{aligned}
\triangle_{1}= & \theta^{2} M_{1}^{2} Z_{1}^{\prime}\left(M_{1}\right) \\
= & -S \theta^{2}+D[h+c \theta(1-r)]\left(\theta M_{1} e^{\theta M_{1}}-e^{\theta M_{1}}+1\right)+\frac{p I_{d} D \theta^{2} M_{1}^{2}}{2} \\
& +\frac{I_{c} \theta^{2}}{2 p D}\left[2 B_{1}^{2} \theta M_{1} e^{2 \theta M_{1}}-B_{1}^{2} e^{2 \theta M_{1}}-2 B_{1} W_{1} \theta M_{1} e^{\theta M_{1}}+2 B_{1} W_{1} e^{\theta M_{1}}-W_{1}^{2}\right] .
\end{aligned}
$$

Now, since $M_{1} \geq \overline{W_{1}}$, Theorem 1 (C) implies that

$$
\triangle_{1}>\triangle_{2} .
$$

Case III. Policy II is adopted and $M_{2}<\overline{W_{3}}$.

Let

$$
\begin{aligned}
\triangle_{46} & =\theta^{2} M_{2}^{2} Z_{4}^{\prime}\left(M_{2}\right)=\theta^{2} M_{2}^{2} Z_{6}^{\prime}\left(M_{2}\right) \\
& =-S \theta^{2}+D(h+c \theta)\left(\theta M_{2} e^{\theta M_{2}}-e^{\theta M_{2}}+1\right)+\frac{p I_{d} D \theta^{2} M_{2}^{2}}{2} \\
& >\triangle_{25}=\triangle_{2}
\end{aligned}
$$

and

$$
\begin{aligned}
\triangle_{63} & =\theta^{2}\left(\overline{W_{3}}\right)^{2} Z_{4}^{\prime}\left(\overline{W_{3}}\right)=\theta^{2}\left(\overline{W_{3}}\right)^{2} Z_{3}^{\prime}\left(\overline{W_{3}}\right) \\
& =-S \theta^{2}+D(h+c \theta)\left(\theta \overline{W_{3}} e^{\theta \overline{W_{3}}}-e^{\theta \overline{W_{3}}}+1\right)+\frac{p I_{d} D \theta^{2} M_{2}^{2}}{2}
\end{aligned}
$$

Since $M_{2}<\overline{W_{3}}$, Theorem 1 (B) implies that

$$
\triangle_{63}>\triangle_{46}>\triangle_{25}=\triangle_{2}
$$

Case IV. Policy II is adopted and $M_{2} \geq \overline{W_{3}}$.

Let

$$
\begin{aligned}
\triangle_{4} & =\theta^{2} M_{2}^{2} Z_{4}^{\prime}\left(M_{2}\right) \\
& =-S \theta^{2}+D(h+c \theta)\left(\theta M_{2} e^{\theta M_{2}}-e^{\theta M_{2}}+1\right)+\frac{p I_{d} D \theta^{2} M_{2}^{2}}{2} \\
& =\triangle_{46}>\triangle_{25}=\triangle_{2}
\end{aligned}
$$

and

$$
\begin{aligned}
\triangle_{3}= & \theta^{2} M_{2}^{2} Z_{3}^{\prime}\left(M_{2}\right) \\
= & -S \theta^{2}+D(h+c \theta)\left(\theta M_{2} e^{\theta M_{2}}-e^{\theta M_{2}}+1\right)+\frac{p I_{d} D \theta^{2} M_{2}^{2}}{2} \\
& +\frac{I_{c} \theta^{2}}{2 p D}\left[2 B_{3}^{2} \theta M_{2} e^{2 \theta M_{2}}-B_{3}^{2} e^{2 \theta M_{2}}-2 B_{3} W_{3} \theta M_{2} e^{\theta M_{2}}+2 B_{3} W_{3} e^{\theta M_{2}}-W_{3}^{2}\right] .
\end{aligned}
$$

Thus, since $M_{2} \geq \overline{W_{3}}$, Theorem 1 (D) implies that

$$
\triangle_{3} \geq \triangle_{4}
$$


Henceforth, in our investigation, we assume that

$$
\begin{gathered}
G>0, \\
3 B_{1}>A_{1}
\end{gathered}
$$

and

$$
3 B_{3}>A_{3} \text {. }
$$

Theorem 1 (E) to Theorem $1(\mathrm{H})$, together, imply that the function $Z_{i}(T)$ is convex when $T>0$ for all $i=1,2,3,4,5,6$. Let $T_{i}$ denote the root of the following equation:

$$
Z_{i}(T)=0 \quad(i=1,2,3,4,5,6)
$$

From the convexity of the function $Z_{i}(T)$ when $T>0$, we conclude that

$$
Z_{i}^{\prime}(T)= \begin{cases}<0 & \text { if } 0<T<T_{i} \\ =0 & \text { if } T=T_{i} \\ >0 & \text { if } T>T_{i} .\end{cases}
$$

Therefore, clearly, the function $Z_{i}(T)$ is decreasing on $\left(0, T_{i}\right]$ and increasing on $\left[T_{i}, \infty\right)$ for $i=1,2,3,4,5,6$.

Proposition 1. Suppose that Policy I is adopted and $M_{1}<\overline{W_{1}}$. Then the following assertions hold true:

(A) If $\triangle_{25}>0$, then $T_{1}^{*}=T_{2}$.

(B) If $\triangle_{25} \leq 0<\triangle_{51}$, then $T_{1}^{*}=T_{5}$.

(C) If $\triangle_{51} \leq 0$, then $T_{1}^{*}=T_{1}$.

\section{Proof.}

(A) If $\triangle_{25}>0$, then $\triangle_{51}>\triangle_{25}>0$. From Equations (73a), (73b) and (73c), we thus find that

(i) $\quad Z_{2}(T)$ is decreasing on $\left(0, T_{2}\right]$ and increasing on $\left[T_{2}, M_{1}\right]$.

(ii) $\quad Z_{5}(T)$ is increasing on $\left[M_{1}, \overline{W_{1}}\right]$.

(iii) $Z_{1}(T)$ is increasing on $\left[\overline{W_{1}}, \infty\right)$.

Since the function $\operatorname{TVC}_{1}(T)$ is continuous when $T>0$ if $M_{1}<\overline{W_{1}}$, Equations (15a), (15b) and (15c) and the above observations (i) to (iii) imply that $T_{1}^{*}=T_{2}$.

(B) If $\triangle_{25} \leq 0<\triangle_{51}$, from Equations (73a), (73b) and (73c), we find that

(iv) $\quad Z_{2}(T)$ is decreasing on $\left(0, M_{1}\right]$.

(v) $Z_{5}(T)$ is decreasing on $\left[M_{1}, T_{5}\right]$ and increasing on $\left[T_{5}, \overline{W_{1}}\right]$.

(vi) $\quad Z_{1}(T)$ is increasing on $\left[\overline{W_{1}}, \infty\right)$.

Since the function $\operatorname{TVC}_{1}(T)$ is continuous when $T>0$ if $M_{1}<\overline{W_{1}}$, Equations (15a), (15b) and (15c), together with the above observations (iv) to (vi), imply that $T_{1}^{*}=T_{5}$.

(C) If $\triangle_{51} \leq 0$, then $\triangle_{25}<\triangle_{51} \leq 0$. From Equations (73a), (73b) and (73c), we obtain

(vii) $Z_{2}(T)$ is decreasing on $\left(0, M_{1}\right]$.

(viii) $Z_{5}(T)$ is decreasing on $\left[M_{1}, \overline{W_{1}}\right]$.

(ix) $\quad Z_{1}(T)$ is decreasing on $\left[\overline{W_{1}}, T_{1}\right]$ and increasing on $\left[T_{1}, \infty\right)$.

Since $\operatorname{TVC}_{1}(T)$ is continuous on $T>0$ if $M_{1}<\overline{W_{1}}$, Equations (15a), (15b) and (15c), and the above observations (vii) to (ix), imply that $T_{1}^{*}=T_{1}$. 
Proposition 2. Suppose that Policy I is adopted and $M_{1} \geq \overline{W_{1}}$. Then the following assertions hold true:

(A) If $\triangle_{2}>0$, then $T_{1}^{*}=T_{2}$.

(B) If $\triangle_{2} \leq 0<\triangle_{1}$, then $T_{1}^{*}=M_{1}$.

(C) If $\triangle_{1} \leq 0$, then $T_{1}^{*}=M_{1}$ or $T_{1}$ is associated with the least cost.

\section{Proof.}

(A) If $\triangle_{2}>0$, then $\triangle_{1} \geq \triangle_{2}>0$. From Equations (73a), (73b) and (73c), we have

(i) $\quad Z_{2}(T)$ is decreasing on $\left(0, T_{2}\right]$ and increasing on $\left[T_{2}, M_{1}\right]$.

(ii) $\quad Z_{1}(T)$ is increasing on $\left(M_{1}, \infty\right)$.

Since $Z_{1}\left(M_{1}\right)>Z_{2}\left(M_{1}\right)$, Equations (18a) and (18b), together with the above observations (i) and (ii), imply that $T_{1}^{*}=T_{2}$.

(B) If $\triangle_{2} \leq 0<\triangle_{1}$, from Equations (73a), (73b) and (73c), we have

(iii) $\quad Z_{2}(T)$ is decreasing on $\left(0, M_{1}\right]$.

(iv) $\quad Z_{1}(T)$ is increasing on $\left(M_{1}, \infty\right)$.

Since $Z_{1}\left(M_{1}\right)>Z_{2}\left(M_{1}\right)$, Equations (18a) and (18b) and the above observations (iii) and (iv) imply that $T_{1}^{*}=M_{1}$.

(C) If $\triangle_{1} \leq 0$, then $\triangle_{2} \leq \triangle_{1} \leq 0$. Thus, from Equations (73a), (73b) and (73c), we get

(v) $\quad Z_{2}(T)$ is decreasing on $\left(0, M_{1}\right]$.

(vi) $\quad Z_{1}(T)$ is decreasing on $\left(M_{1}, T_{1}\right]$ and increasing on $\left[T_{1}, \infty\right)$.

Since $Z_{1}\left(M_{1}\right)>Z_{2}\left(M_{1}\right)$, Equations (18a) and (18b), together with the above observations (v) and (vi), imply that $T_{1}^{*}=M_{1}$ or $T_{1}$ is associated with the least cost.

Proposition 3. Suppose that Policy II is adopted and $M_{2}<\overline{W_{3}}$. Then the following assertions hold true:

(A) If $\triangle_{46}>0$, then $T_{2}^{*}=T_{4}$.

(B) If $\triangle_{46} \leq 0<\triangle_{63}$, then $T_{2}^{*}=T_{6}$.

(C) If $\triangle_{63} \leq 0$, then $T_{2}^{*}=T_{3}$.

Proof. The proof of Proposition 3 is similar to that of Proposition 1. We, therefore, choose to skip the details involved.

Proposition 4. Suppose that Policy II is adopted and $M_{2} \geq \overline{W_{3}}$. Then the following assertions hold true:

(A) If $\triangle_{4}>0$, then $T_{2}^{*}=T_{4}$.

(B) If $\triangle_{4} \leq 0<\triangle_{3}$, then $T_{2}^{*}=M_{2}$.

(C) If $\triangle_{3} \leq 0$, then $T_{2}^{*}=M_{2}$ or $T_{3}$ is associated with the least cost.

Proof. The proof of Proposition 4 would run parallel to that of Proposition 2. The details involved are, therefore, omitted.

Theorem 2. Suppose that

$$
M_{1}<\overline{W_{1}} \text { and } M_{2}<\overline{W_{3}} .
$$

Then each of the following assertions holds true: 
(i) If $\triangle_{25}>0$, then $T^{*}=T_{2}$ or $T_{4}$ is associated with the least cost.

(ii) If $\triangle_{25} \leq 0<\triangle_{51}$ and $\triangle_{46}>0$, then $T^{*}=T_{5}$ or $T_{4}$ is associated with the least cost.

(iii) If $\triangle_{25} \leq 0<\triangle_{51}$ and $\triangle_{46} \leq 0<\triangle_{63 \prime \prime} T^{*}=T_{5}$ or $T_{6}$ is associated with the least cost.

(iv) If $\triangle_{25} \leq 0<\triangle_{51}$ and $\triangle_{63} \leq 0$, then $T^{*}=T_{5}$ or $T_{3}$ is associated with the least cost.

(v) If $\triangle_{51} \leq 0$ and $\triangle_{46}>0$, then $T^{*}=T_{1}$ or $T_{4}$ is associated with the least cost.

(vi) If $\triangle_{51} \leq 0$ and $\triangle_{46} \leq 0<\triangle_{63}$, then $T^{*}=T_{1}$ or $T_{6}$ is associated with the least cost.

(vii) If $\triangle_{51} \leq 0$ and $\triangle_{63} \leq 0$, then $T^{*}=T_{1}$ or $T_{3}$ is associated with the least cost.

Proof. The demonstration of Theorem 2 would make use of Propositions 1 and 3.

Theorem 3. Suppose that $M_{1}<\overline{W_{1}}$ and $M_{2} \geq \overline{W_{3}}$. Then each of the following assertions holds true:

(i) If $\triangle_{25}>0$, then $T^{*}=T_{2}$ or $T_{4}$ is associated with the least cost.

(ii) If $\triangle_{25} \leq 0<\triangle_{51}$ and $\triangle_{4}>0$, then $T^{*}=T_{5}$ or $T_{4}$ is associated with the least cost.

(iii) If $\triangle_{25} \leq 0<\triangle_{51}$ and $\triangle_{4} \leq 0<\triangle_{3}$, then $T^{*}=T_{5}$ or $M_{2}$ is associated with the least cost.

(iv) If $\triangle_{25} \leq 0<\triangle_{51}$ and $\triangle_{3} \leq 0$, then $T^{*}=T_{5}$, then $M_{2}$ or $T_{3}$ is associated with the least cost.

(v) If $\triangle_{51} \leq 0$ and $\triangle_{4}>0$, then $T^{*}=T_{1}$ or $T_{4}$ is associated with the least cost.

(vi) If $\triangle_{51} \leq 0$ and $\triangle_{4} \leq 0<\triangle_{3}$, then $T^{*}=T_{1}$ or $M_{2}$ is associated with the least cost.

(vii) If $\triangle_{51} \leq 0$ and $\triangle_{3} \leq 0$, then $T^{*}=T_{1}, M_{2}$ or $T_{3}$ is associated with the least cost.

Proof. The proof of Theorem 3 follows from Propositions 1 and 4.

Theorem 4. Suppose that $M_{1} \geq \overline{W_{1}}$ and $M_{2}<\overline{W_{3}}$. Then each of the following assertions holds true:

(i) If $\triangle_{2}>0$, then $T^{*}=T_{2}$ or $T_{4}$ is associated with the least cost.

(ii) If $\triangle_{2} \leq 0<\triangle_{1}$ and $\triangle_{46}>0$, then $T^{*}=M_{1}$ or $T_{4}$ is associated with the least cost.

(iii) If $\triangle_{2} \leq 0<\triangle_{1}$ and $\triangle_{46} \leq 0<\triangle_{63}$, then $T^{*}=M_{1}$ or $T_{6}$ is associated with the least cost.

(iv) If $\triangle_{2} \leq 0<\triangle_{1}$ and $\triangle_{63} \leq 0$, then $T^{*}=M_{1}$ or $T_{3}$ is associated with the least cost.

(v) If $\triangle_{1} \leq 0$ and $\triangle_{46}>0$, then $T^{*}=M_{1}, T_{1}$ or $T_{4}$ is associated with the least cost.

(vi) If $\triangle_{1} \leq 0$ and $\triangle_{46} \leq 0<\triangle_{63}$, then $T^{*}=M_{1}, T_{1}$ or $T_{6}$ is associated with the least cost.

(vii) If $\triangle_{1} \leq 0$ and $\triangle_{63} \leq 0$, then $T^{*}=M_{1}, T_{1}$ or $T_{3}$ is associated with the least cost.

Proof. Theorem 4 can be proven by applying Propositions 2 and 3 .

Theorem 5. Suppose that $M_{1} \geq \overline{W_{1}}$ and $M_{2} \geq \overline{W_{3}}$. Then each of the following assertions holds true:

(i) If $\triangle_{2}>0$, then $T^{*}=T_{2}$ or $T_{4}$ is associated with the least cost.

(ii) If $\triangle_{2} \leq 0<\triangle_{1}$ and $\triangle_{4}>0$, then $T^{*}=M_{1}$ or $T_{4}$ is associated with the least cost.

(iii) If $\triangle_{2} \leq 0<\triangle_{1}$ and $\triangle_{4} \leq 0<\triangle_{3}$, then $T^{*}=M_{1}$ or $M_{2}$ is associated with the least cost.

(iv) If $\triangle_{2} \leq 0<\triangle_{1}$ and $\triangle_{3} \leq 0$, then $T^{*}=M_{1}, M_{2}$ or $T_{3}$ is associated with the least cost.

(v) If $\triangle_{1} \leq 0$ and $\triangle_{4}>0$, then $T^{*}=M_{1}, T_{1}$ or $T_{4}$ is associated with the least cost.

(vi) If $\triangle_{1} \leq 0$ and $\triangle_{4} \leq 0<\triangle_{3}$, then $T^{*}=M_{1}, T_{1}$ or $M_{2}$ is associated with the least cost.

(vii) If $\triangle_{1} \leq 0$ and $\triangle_{3} \leq 0$, then $T^{*}=M_{1}, T_{1}, M_{2}$ or $T_{3}$ is associated with the least cost.

Proof. It is easy to derive Theorem 5 by making use of Propositions 2 and 4.

\section{Discussions Concerning Theorem 1 of Chang and Teng [41]}

(A) About Theorem 1 (1) in Chang and Teng [41]:

Equation (29) reveals that

$$
Z\left(T^{*}\right)=\min \left\{\operatorname{TVC}_{1}\left(T_{1}^{*}\right), \operatorname{TVC}_{2}\left(T_{2}^{*}\right)\right\}
$$


Therefore, clearly, we have $T^{*}=T_{1}^{*}$ (Policy I) or $T_{2}^{*}$ (Policy II) associated with the least cost. Chang and Teng [41] do not make the comparison between $\operatorname{TVC}_{1}\left(T_{1}^{*}\right)$ and $\mathrm{TVC}_{2}\left(T_{2}^{*}\right)$. Consequently, in general, the claimed assertion of Theorem 1 (1) in Chang and Teng [41] is not necessarily true.

(B) About Theorem 1 (2) in the paper by Chang and Teng [41]:

If

$$
2 S=\left[h+c \theta(1-r)+p I_{d}\right] D M_{1}^{2},
$$

our Theorem 1 (B) (ii) implies that

$$
\begin{aligned}
Z_{2}^{\prime}\left(M_{1}\right) & =\frac{1}{\theta^{2} M_{1}^{2}}\left\{-S \theta^{2}+D[h+c \theta(1-r)]\left(\theta M_{1} e^{\theta M_{1}}-e^{\theta M_{1}}+1\right)+\frac{p I_{d} D \theta^{2} M_{1}^{2}}{2}\right\} \\
& >\frac{1}{\theta^{2} M_{1}^{2}}\left\{-S \theta^{2}+D[h+c \theta(1-r)] \frac{\theta^{2} M_{1}^{2}}{2}+\frac{p I_{d} D \theta^{2} M_{1}^{2}}{2}\right\} \\
& =\frac{1}{2 M_{1}^{2}}\left\{-2 S+\left[h+c \theta(1-r)+p I_{d}\right] D M_{1}^{2}\right\} \\
& =0 .
\end{aligned}
$$

Since $Z_{2}^{\prime}\left(M_{1}\right)>0, M_{1}$ is not the optimal solution of $\operatorname{TVC}_{1}(T)$. Therefore, in general, the result claimed in Theorem 1 (2) of Chang and Teng [41] is not true.

(C) About Theorem 1 (3) in the paper by Chang and Teng [41]:

Let $T_{C T}^{*}$ denote the optimal solution obtained by Theorem 1 in Chang and Teng [41]. In this case, we consider the following example.

Example 1. Given $D=500$ units/year, $h=\$ 4 /$ unit/year, $I_{c}=0.09 /$ year,$I_{d}=0.06 /$ year,$c=\$ 30$ per unit, $p=\$ 35$ per unit, $r=0.02, Q=0.07, M_{1}=30$ days $=30 / 365$ years, $M_{2}=56$ days $=56 / 365$ years and $S=\$ 13.85$ per order. Then

$$
\left(h+c \theta+p I_{d}\right) D M_{2}^{2}>2 S>\left[h+c \theta(1-r)+p I_{d}\right] D M_{1}^{2},
$$

$G=2.9839>0, A_{1}=1441.9028, B_{1}=210000, A_{3}=2697.2895, B_{3}=214285.7143, \overline{W_{1}}=0.09775$, $\overline{W_{3}}=0.178696983, M_{1}=0.08219$ years and $M_{2}=0.1787$ years. We thus observe that $M_{1}<\overline{W_{1}}$, $M_{2}<\overline{W_{3}}, 3 B_{1}>A_{1}, 3 B_{1}>A_{1}$ and $3 B_{3}>A_{3}$. Furthermore, we get $\triangle_{25}=-1.59779 \times 10^{-4}<0$, $\triangle_{46}=0.1698>0$ and $\triangle_{51}=0.02795>0$. Then, by applying Theorem 2 (ii) of this paper, we have $T^{*}=T_{5}$ or $T_{4}$. The familiar Intermediate Value Theorem (see, for example, Varberg et al. [42]) can now be used to locate $T_{5}$ and $T_{4}$. We thus find that $T_{5}=0.08231, T_{4}=0.08207, T V C_{1}\left(T_{5}\right)=14950.0759$ and $T_{V C}\left(T_{4}\right)=15176.1460$. Since

$$
T V C_{1}\left(T_{5}\right)<T V C_{2}\left(T_{4}\right),
$$

we have $T^{*}=T_{5}$. Moreover, by applying the Intermediate Value Theorem, we conclude that

$$
0<T_{1}<\overline{W_{1}}
$$

since $\triangle_{51}>0, G>0$ and

$$
\lim _{T \rightarrow 0^{+}} Z_{5}^{\prime}(T)=-\infty .
$$

Therefore, $T_{1}$ does not satisfy Equation (24) in Chang and Teng [41]. Consequently, Theorem 1 (3) in Chang and Teng [41] can be used. We then get $T_{C T}^{*}=T_{4}$. However, the accurate optimum solution of the above Example should be $T^{*}=T_{5}$. Therefore, by contradiction, Theorem 1 (3) in Chang and Teng [41] is not necessarily true. 
(D) About Theorem 1 (4) in the paper by Chang and Teng [41]:

The proof in this case is similar to that in (B) above. Therefore, Theorem 1 (4) in Chang and Teng [41] is not true.

(E) About Theorem 1 (5) in the paper by Chang and Teng [41]:

Our reasoning here is the same as that of (A) above. Therefore, Theorem 1 (5) in the work of Chang and Teng [41] is not necessarily true.

By incorporating (A) to (E) above, it is concluded that in general, Theorem 1 in Chang and Teng [41] is not necessarily true.

\section{Concluding Remarks and Observations}

In our present investigation, we have successfully divided all our mathematical analytic derivations of the annual total relevant $\operatorname{cost} Z(T)$ into the following four cases:

(1) $M_{1}<\bar{W}_{1}$

(2) $M_{1} \geq \bar{W}_{1}$

(3) $M_{2}<\bar{W}_{3}$

(4) $M_{2} \geq \bar{W}_{3}$

When the above Case 2 and Case 4 hold true, the annual total relevant costs in this paper are seen to be consistent with those of Chang and Teng [41]. However, if the above Case 1 and Case 3 hold true, then the annual total relevant costs in the work by Chang and Teng [41] are observed to be incorrect. Furthermore, this paper has also indicates that Theorem 1 in Chang and Teng [41] is based on the assumption that $\theta T$ is small. However, our present investigation does not include this assumption. On the other hand, in general, Theorem 1 in the work by Chang and Teng [41] is not necessarily true. Theorems 2 to 5 in this paper have been fruitfully used to characterize the optimal solutions and to demonstrate the fact that they can locate all optimal solutions of $Z(t)$. By incorporating the above arguments. we conclude that our present investigation has not only removed all those shortcomings in the paper by Chang and Teng [41], but it has also presented solvable ways for the problem considered by Chang and Teng [41]. Consequently, in this paper, we have corrected and substantially improved the work of Chang and Teng [41]. Therefore, it can significantly reduce the cost of the inventory model.

The mathematically correct analytic investigation of the model, which we have presented in this paper, is believed to be useful for correct managerial considerations and right managerial decisions.

The proposed model, for which we have presented a mathematical analytic investigation in this article, is capable of being extended in several different directions. Among other such possibilities of extension and generalization of our study here, it may be worthwhile to extend the constant demand rate to hold true in the case of a more realistic situation when the time-varying demand rate is a function of the time, the selling price, the advertisement of the product quality, and sundry other considerations. Yet another direction for future research on the subject-matter of our present investigation is the possibility of generalization and extension of the model with a view to allowing for shortages, quantity discounts, inflation rates, and other business-related considerations.

Author Contributions: Conceptualization, K.-J.C., J.-J.L. and S.-D.L.; methodology, K.-J.C., J.-J.L., S.-D.L. and H.M.S.; software, S.-D.L. and S.-T.C.; validation, S.-D.L. and H.M.S.; formal analysis, K.-J.C., J.-J.L., S.-D.L. and H.M.S.; investigation, K.-J.C., J.-J.L. and S.-D.L.; resources, K.-J.C., J.-J.L. and S.-D.L.; data curation, S.-D. Lin and S.-T.C.; writing-original draft preparation, K.-J.C., J.-J.L., S.-D.L. and S.-T.C.; writing-review and editing, K.-J.C., J.-J.L., S.-D.L. and H.M.S.; visualization, J.-J.L. and S.-T.C.; supervision, K.-J.C., S.-D.L. and H.M.S.; project administration, K.-J.C., J.-J.L., S.-D.L. and H.M.S.; funding acquisition, Not Applicable.

Funding: This research received no external funding.

Conflicts of Interest: The authors declare no conflicts of interest. 


\section{References}

1. Stokes, J.R. Dynamic cash discounts when sales volume is stochastic. Quart. Rev. Econ. Financ. 2005, 45, 144-160. [CrossRef]

2. Arcelus, F.J.; Shah, N.H.; Srinivasan, G. Retailer's pricing, credit and inventory policies for deteriorating items in response to temporary price/credit incentives. Int. J. Prod. Econ. 2003, 81-82, 153-162. [CrossRef]

3. Hill, N.C.; Riener, K.D. Determining the cash discount in the firm's credit policy. Financ. Manag. 1979, 8 , 68-73. [CrossRef]

4. Huang, Y.-F.; Chung, K.-J. Optimal replenishment and payment policies in the EOQ model under cash discount and trade credit. Asia-Pac. J. Oper. Res. 2003, 20, 177-190.

5. Huang, Y.-F. Optimal retailer's replenishment decisions in the EPQ model under two levels of trade credit policy. Eur. J. Oper. Res. 2007, 176, 1577-1591. [CrossRef]

6. Chung, K.-J.; Huang, T.-S. The optimal retailer's ordering policies for deteriorating items with limited storage capacity under trade credit financing. Int. J. Prod. Econ. 2007, 106, 127-145. [CrossRef]

7. Chung, K.-J. The complete proof on the optimal ordering policy under cash discount and trade credit. Int. J. Syst. Sci. 2010, 41, 467-475. [CrossRef]

8. Huang, K.-N.; Liao, J.-J. A simple method to locate the optimal solution for exponentially deteriorating items under trade credit financing. Comput. Math. Appl. 2008, 56, 965-977. [CrossRef]

9. Ouyang, L.-Y.; Yang, C.-T.; Chan, Y.-L.; Cárdenas-Barrón, L.E. A comprehensive extension of the optimal replenishment decisions under two levels of trade credit policy depending on the order quantity. Appl. Math. Comput. 2013, 224, 268-277.

10. Huang, Y.-F.; Hsu, K.-H. An EOQ model under retailer partial trade credit policy in supply chain. Int. J. Prod. Econ. 2008, 112, 655-664. [CrossRef]

11. Sana, S.S.; Chaudhuri, K.S. A deterministic EOQ model with delays in payments and price discount offers. Eur. J. Oper. Res. 2008, 184, 509-533. [CrossRef]

12. Ho, C.-H.; Ouyang, L.-Y.; Su, C.-H. Optimal pricing, shipment and payment policy for an integrated supplier-buyer inventory model with two-part trade credit. Eur. J. Oper. Res. 2008, 187, 496-510. [CrossRef]

13. Feng, H.-R.; Li, J.; Zhao, D. Retailer's optimal replenishment and payment policies in the EPQ model under cash discount and two-level trade credit policy. Appl. Math. Model. 2013, 37, 3322-3339. [CrossRef]

14. Yang, C.-T. The optimal order and payment policies for deteriorating items in discount cash flows analysis under the alternatives of conditionally permissible delay in payments and cash discount. Top 2010, 18, 429-443. [CrossRef]

15. Taleizadeh, A.A.; Sarkar, B.; Hasani, M. Delayed payment policy in multi-product single-machine economic production quantity model with repair failure and partial backordering. J. Ind. Manag. Optim. 2019, 1684-1688. [CrossRef]

16. Ghare, P.M.; Scharder, G.P. A model for exponentially decaying inventory. J. Ind. Engrg. 1963, 14, $238-243$.

17. Philip, G.C. A generalized EOQ model for items with Weibull distribution deterioration. AIIE Trans. 1974, 6, 159-162. [CrossRef]

18. Shah, Y.K. An order-level lot-size inventory model for deteriorating items. AIIE Trans. 1977, 9, $108-112$. [CrossRef]

19. Aggarwal, S.P.; Jaggi, C.K. Ordering policies of deteriorating items under permissible delay in payments. J. Oper. Res. Soc. 1995, 46, 658-662. [CrossRef]

20. Sarkar, B.; Saren, S.; Cárdenas-Barrón, L.E. An inventory model with trade-credit policy and variable deterioration for fixed lifetime products. Ann. Oper. Res. 2015, 229, 677-702. [CrossRef]

21. Liao, J.-J.; Huang, K.-N.; Chung, K.-J.; Ting, P.-S.; Lin, S.-D.; Srivastava, H.M. Some mathematical analytic arguments for determining valid optimal lot size for deteriorating items with limited storage capacity under permissible delay in payments. Appl. Math. Inform. Sci. 2016, 10, 915-925. [CrossRef]

22. Chang, H.-J.; Hung, C.-H.; Dye, C.-Y. An inventory model for deteriorating items with linear trend demand under the condition of permissible delay in payments. Prod. Plan. Control. 2001, 12, 274-282. [CrossRef]

23. Manna, S.K.; Chaudhuri, K.S. An EOQ model with ramp type demand rate, time dependent deterioration rate, unit production cost and shortages. Eur. J. Oper. Res. 2006, 171, 557-566. [CrossRef] 
24. Skouri, K.; Konstantaras, I.; Manna, S.K. Chaudhuri, K.S.; Inventory models with ramp type demand rate, time dependent deterioration rate, unit production cost and shortages. Ann. Oper. Res. 2011, 191, 73-95. [CrossRef]

25. Sett, B.K.; Sarkar, B.; Goswami, A. A two-warehouse inventory model with increasing demand and time varying deterioration. Sci. Iran. 2012, 19, 1969-1977. [CrossRef]

26. Sarkar, B. An EOQ model with delay in payments and time varying deterioration rate. Math. Comput. Model. 2012, 55, 367-377. [CrossRef]

27. Sarkar, B.; Sarkar, S. An improved inventory model with partial backlogging, time varying deterioration and stock-dependent demand. Econ. Model. 2013, 30, 924-932. [CrossRef]

28. Chung, K.-J.; Cárdenas-Barrón, L.E.; Ting, P.-S. An inventory model with non-instantaneous receipt and exponentially deteriorating items for an integrated three layer supply chain system under two levels of trade credit. Int. J. Prod. Econ. 2014, 155, 310-317. [CrossRef]

29. Chung, K.-J.; Liao, J.-J.; Ting, P.-S.; Lin, S.-D.; Srivastava, H.M. A unified presentation of inventory models under quantity discounts, trade credits and cash discounts in the supply chain management. Revista de la Real Academia de Ciencias Exactas, Físicas y Naturales Serie A Matemáticas (RACSAM) 2018, 112, 509-538. [CrossRef]

30. Chung, K.-J.; Lin, S.-D.; Srivastava, H.M. The complete solution procedures for the mathematical analysis of some families of optimal inventory models with order-size dependent trade credit and deterministic and constant demand. Appl. Math. Comput. 2012, 219, 141-156. [CrossRef]

31. Chung, K.-J.; Lin, S.-D.; Srivastava, H.M. The inventory models under conditional trade credit in a supply chain system. Appl. Math. Model. 2013, 37, 10036-10052. [CrossRef]

32. Liao, J.-J.; Huang, K.-N.; Chung, K.-J.; Lin, S.-D.; Ting, P.-S.; Srivastava, H.M. Mathematical analytic techniques for determining the optimal ordering strategy for the retailer under the permitted trade-credit policy of two levels in a supply chain system. Filomat 2018, 32, 4195-4207. [CrossRef]

33. Liao, J.-J.; Huang, K.-N.; Chung, K.-J.; Ting, P.-S.; Lin, S.-D.; Srivastava, H.M. Lot-sizing policies for deterioration items under two-level trade credit with partial trade credit to credit-risk retailer and limited storage capacity. Math. Methods Appl. Sci. 2017, 40, 2122-2139. [CrossRef]

34. Srivastava, H.M.; Chung, K.-J.; Liao, J.-J.; Lin, S.-D. and Chuang, S.-T. Some modified mathematical analytic derivations of the annual total relevant cost of the inventory model with two levels of trade credit in the supply chain system. Math. Methods Appl. Sci. 2019, 42, 3967-3977. [CrossRef]

35. Sarker, B.R.; Mukherjee, S.; Balan, C.V. An order-level lot size inventory model with inventory-level dependent demand and deterioration. Int. J. Prod. Econ. 1997, 48, 227-236. [CrossRef]

36. Wu, J.-A.; Teng, J.-T.; Chan, Y.-L. Inventory policies for perishable products with expiration dates and advance-cash-credit payment schemes. Int. J. Syst. Sci. Oper. Logist. 2018, 5, 310-326. [CrossRef]

37. Jaggi, C.K.; Gupta, M.; Kausar, A.; Tiwari, S. Inventory and credit decisions for deteriorating items with displayed stock dependent demand in two-echelon supply chain using Stackelberg and Nash equilibrium solution. Ann. Oper. Res. 2019, 274, 309-329. [CrossRef]

38. Kawale, S.; Sanas, Y. A review on inventory models under trade credit. Int. J. Math. Oper. Res. 2017, 11, 520-543. [CrossRef]

39. Sarker, B.R.; Jamal, A.M.M.; Wang, S.-J. Supply chain models for perishable products under inflation and permissible delay in payment. Comput. Oper. Res. 2000, 27, 59-75. [CrossRef]

40. Shah, N.H.; Soni, H.N.; Patel, K.A. Optimizing inventory and marketing policy for non-instantaneous deteriorating items with generalized type deterioration and holding cost rates. Omega 2013, 41, 421-430. [CrossRef]

41. Chang, C.-T.; Teng, J.-T. Retailer's optimal ordering policy under supplier credits. Math. Methods Oper. Res. 2004, 60, 471-483. [CrossRef]

42. Varberg, D.; Purcell, E.J.; Rigdon, S.E. Calculus, 9th ed.; Pearson Education Incorporated: Upper Saddle River, NJ, USA, 2007.

(C) 2019 by the authors. Licensee MDPI, Basel, Switzerland. This article is an open access article distributed under the terms and conditions of the Creative Commons Attribution (CC BY) license (http:/ / creativecommons.org/licenses/by/4.0/). 